Received September 12, 2012

Revised December 12, 2012

Accepted December 22, 2012

\title{
International Comparisons of Income Inequality and Welfare in the $1980 \mathrm{~s}^{*}$
}

\author{
PARK, Chanyong ${ }^{* *}$
}

The main purpose of this paper is to compare the income inequality and welfare levels between countries selected on a worldwide basis in the 1980s. As analytical tools, Lorenz curves, the Gini coefficients and generalized Lorenz curves are used. Implicit in our analysis is the presumption that welfare is a function of the "size" of total income and distributional equality. This study makes it possible to observe the welfare levels of the selected countries by combining real GDP per capita with income decile. It thus contributes to increasing our understanding of household income inequality and welfare levels in the 1980s. Data for this study is from the "Households Income and Expenditure Statistics, 4th edition" (HIES), one of a series published by the International Labour Organization.

Keywords: Gini, Lorenz Curve, Generalized Lorenz Curve, Income Inequality, Welfare, HIES, ILO

* The author would like to thank Professor Mehran F.(Université de Neuchâtel, Switzerland) and Dr. Tabatabai H.(ILO) for their excellent comments on this paper. This research was supported by a grant from Andong National University.

** Professor, Andong National University

E-mail : parkch@andong.ac.kr 


\section{INTRODUCTION}

$\mathrm{T}$ he aim of this study is to compare the income inequality and welfare levels between countries selected on a worldwide basis in the 1980s, that is, just before the end of the Cold War. While the studies on economic inequality comparisons have had a long history, welfare comparisons of income distribution have been investigated since the early 1980s. Shorrocks (1983) introduced a generalized Lorenz curve which takes the (ordinary) Lorenz curve and scales it by the average income under the assumption that a population prefers not only economic equality but also higher real incomes. A number of important studies were subsequently made, among which are those of Kakwani (1984), Dardanoni-Lambert (1988) and Lambert (1989). Kakwani studied the success rate of welfare evaluation by the generalized Lorenz curve in processing 248 pair-wise comparisons between the 1970 distributions of real GDP in U.S. dollar terms for 23 countries and found that generalized Lorenz curves are likely to cross less often than (ordinary) Lorenz curves. Dardanoni-Lambert and Lambert proved that information on variances can sometimes be adduced to provide a (weaker) welfare prescription when generalized Lorenz curves cross. Atkinson (2007) and Chiu (2007) provided useful analyses of the implications of third-degree stochastic dominance on measurement of inequality and social welfare of income distribution. On the basis of the Shorrocks framework of analysis, this study makes it possible to observe the welfare levels of the selected countries by combining real GDP per capita with decile. Data for this study is from the "Households Income and Expenditure Statistics, 4th edition"(HIES), one of a series published by the International Labour Office, and might provide the most complete information on the subject at that period. For this purpose, the first part of the paper measures the economic inequality levels of the 51 countries whose data are available in the HIES (see Table 1). It also ranks the household income inequality levels of the only 23 countries to facilitate international comparisons (see Table 2). In the second part, mean income levels are introduced into the Lorenz curves (the so-called "generalized Lorenz curve") of the 23 countries. Welfare is considered as a function of the "size" of total income and distributional equality, that is, an increasing equality with mean income represents an increase in welfare. 


\section{STATISTICAL SOURCES AND METHODS}

\section{Statistical Sources and Income Concept/Unit}

The HIES (4th edition) contains the results of household income and expenditure surveys carried out in 82 countries and areas, which were mainly based on replies to the ILO questionnaires on the HIES. The household income data of each country in the HIES are basically provided in grouped form, giving a) average household income (or expenditure) classes, b) average household income (or expenditure) of each income (or expenditure) class, c) household share in percentage of each income class, and d) average household size of each income class. However, the presentation of data varies from country to country, so that a range of adjustment procedures was required, before the use of data, to produce the final harmonized result.

The household income concept used for the HIES is the sum of income as defined by the Resolution adopted by the Twelfth International Conference of Labour Statisticians (1973) of the ILO. It includes wages and salaries in cash as well as in kind, entrepreneurial income, property income and transfers and other benefits received. This is gross income before deduction of income or other direct taxes and social security contributions. The ILO questionnaire on the HIES, sent to different countries, was designed on the basis of this Resolution, as far as possible, to facilitate comparative analysis.

The income unit which corresponds to the income concept of this study is the household. The concepts and definitions of a household of the countries in the HIES were quite similar, with a few exceptions. Most of the countries' national surveys covered all types of private households, including one-person households, but usually excluded institutional populations, armed forces and foreigner's families.

Income data in the HIES are shown by two types of income units: average household income and/or average per capita household income. When there is complete information concerning household size, composition, number of earners and collective goods, it is evident that household income per equivalent unit is a better criterion of economic welfare than household income per household or per capita household income. An equivalence scale is a device to convert the incomes of different income unit types to a common base measuring income-unit purchasing power. However, household income data in the HIES refer to only average household size for each income stratum. In that case, per capita household income may be used as "second best". In this study, however, the framework of analysis has been formulated only in terms of household income per household to allow comparative study. 


\section{Statistical Methods for Estimating the Gini coefficients and Deciles}

Statistical data in the HIES have several deficiencies: limited references to groups or populations, data collection at irregular intervals, and differences in definitions and classifications, which vary from country to country, and even for the same country over a period of time. Furthermore, many countries, especially developing ones, very often apply a varying scope to their national household income and expenditure survey, and in some cases do not even have an adequate national survey system. The most usual difference seen in household income data between countries pertains to the number of subdivided income ranges. Of the 82 countries in the HIES, only two subdivided income data with over 20 strata (Ethiopia and Turkey), about half of all countries presented in the HIES have 10 to 20 income classes, and many countries classify them with less than 8 strata. In fact the number of strata is an important variable for data analysis. In order to minimize these deficiencies, as statistical methods for estimating the Gini coefficients and deciles, we applied a general interpolation method and Kakwani-Podder method for the Gini coefficient and the Pareto method and the Beta Lorenz curve method for deciles as shown in the Appendix.

\section{HOUSEHOLD INCOME INEQUALITY}

The economic inequality levels of the 51 countries whose data are available in the HIES( $4^{\text {th }}$ edition) were measured by using the above estimation methods. Selected countries in the HIES were those: 1) whose national surveys covered urban areas and/or rural areas and/or the whole country, 2) whose household income data were subdivided into more than three strata, and 3) whose data provided complete information on the mean income (or expenditure), household share and household size of each income class.

As shown in Table 1, the results are not consistent in terms of the areas covered by the national survey and the measurement unit. To facilitate the international comparison, 23 countries were selected in Table 1 . The selection has mainly involved those countries: a) whose household income inequality statistics were available, b) whose national surveys covered the whole country, and c) whose national survey covered all private households.

The result of selection is shown in Table 2. This table represents the selected countries' inequality levels, i.e., comparable data on household income distribution for ten developed, one socialist and 13 developing countries. All the selected countries have been ranked by numerical order according to Gini coefficients. A glance at the table reveals the following facts. Japan achieves the most equal income distribution among the countries, and the Netherlands follows closely. 
The UK and the USA have relatively skewed income distribution among the developed countries. As to a socialist country, there are some risks of misinterpretation that we directly compare the inequality degree of a socialist country with that of a non-socialist one. In fact, the major difficulties may be those of the comparability of data from countries in different economic systems and of the proper interpretation of household income of the socialist countries, which requires the availability of a considerable degree of knowledge and awareness of the institutional features of the countries.

In Table 2, most industrialized countries are generally ranked at the top with relatively equal income distribution, and developing countries such as Greece, Pakistan and Cyprus are shown to have a quite favorable income distribution. Botswana, Qatar and Swaziland have the most unequal income distribution among the selected countries. However, inspection of Table 2 reveals the weakness of this ranking. In this table, the income shares of the $1^{\text {st }}$ to the $3^{\text {rd }}$ decile of each country are ranked on the basis of their size of income share. For example, the income share of the $1^{\text {st }}$ decile of Yugoslavia is 3.93 percent, and its subscript number " 1 " means that the share is the biggest among all the income shares of the $1^{\text {st }}$ decile of the countries. However, the country rankings are inconsistent with those of income shares of the decile in many cases. The income share of the $1^{\text {st }}$ decile of Japan is therefore smaller than that of Yugoslavia in spite of the fact that Japan has a more equal income distribution than Yugoslavia. With the subscript numbers, we can find several similar cases: West Germany-Pakistan, UK-Mexico, USA-Philippines, and so on. Taking the case of W. Germany-Pakistan as an example: while the Gini coefficient of W. Germany is lower than that of Pakistan ( 0.323 and 0.356, respectively), the cumulated income share of the bottom $1^{\text {st }}$ to $3^{\text {rd }}$ decile of $\mathrm{W}$. Germany is smaller than that of Pakistan, which means that the Lorenz curves of these two counties cross.

TABLE 1: The Results of Estimating the Gini coefficients and Deciles

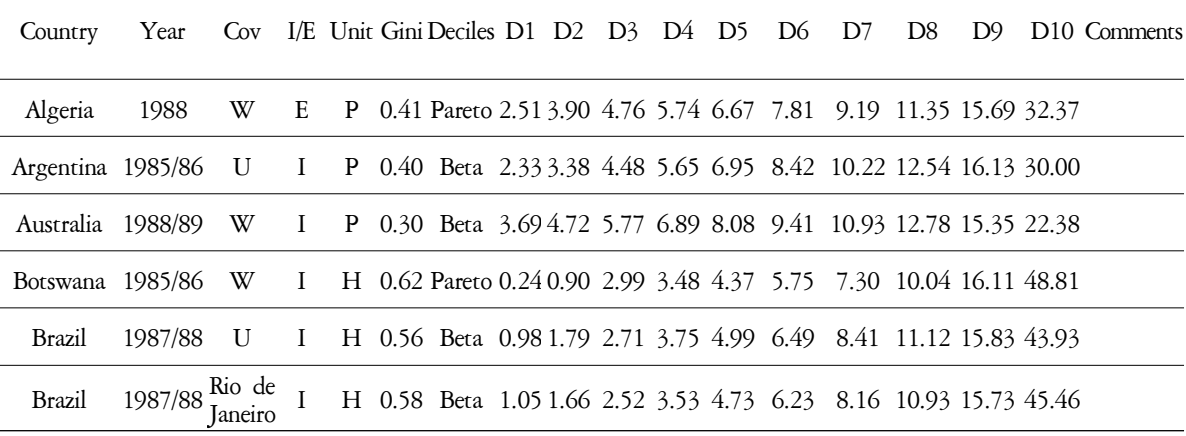




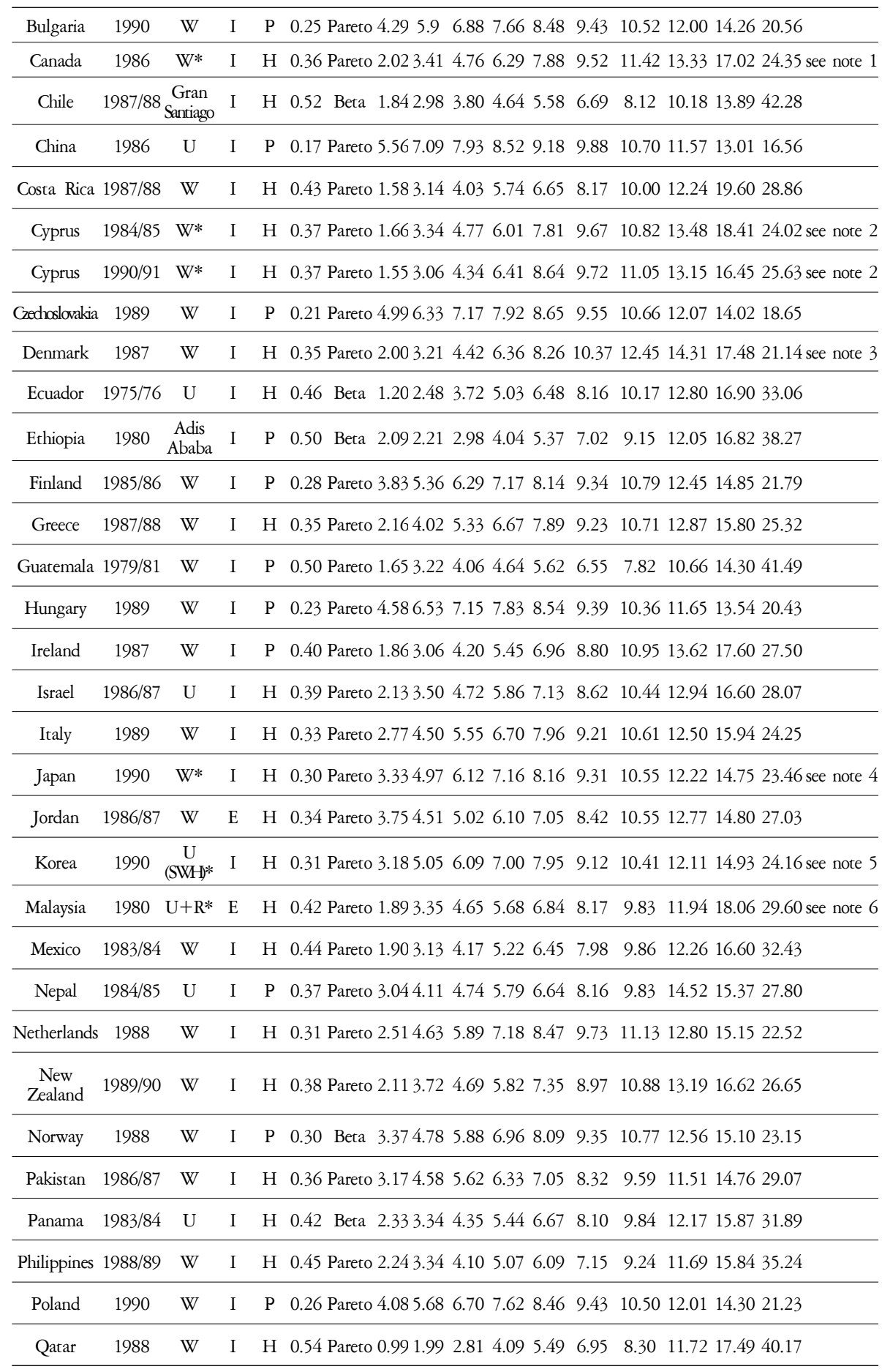




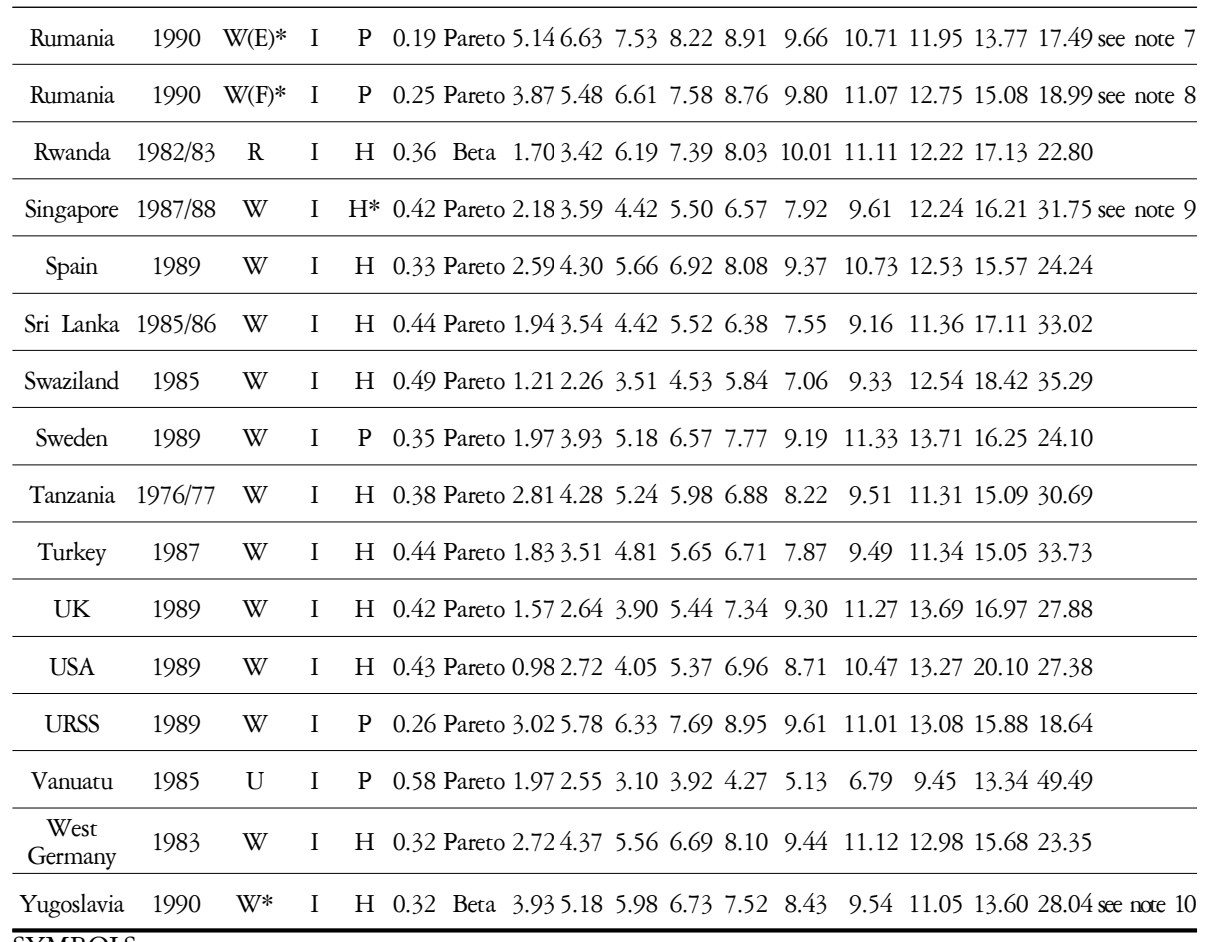

\section{SYMBOLS}

Cov: areas covered by the national survey, W: Whole country, U: Urban Areas, R: Rural Areas I: Income, E: Expenditure H: Household, P: Per Capita,

Pareto: Deciles are computed by the Pareto Method

Beta: Deciles are computed by the Beta Lorenz curve method

\section{NOTES}

*1: Yukon and Northwest Territories are excluded

*2: Government controlled areas of Cyprus.

*3: Greenland and the Faeroe Islands are excluded

*4: One person households are not included in the survey

*5: Salary and wage earners households in urban areas, and one person households are not included in the survey

*6: Peninsular, urban and rural

*7: Employees' households

*8: Farmers' households

*9: One person households are not included in the survey

*10: Prior to 01. 01.1992 and excluding province of Kosovo

Source: Author's estimation from the HIES(4th edition) 
TABLE 2: Income share of deciles of households and Gini coefficient

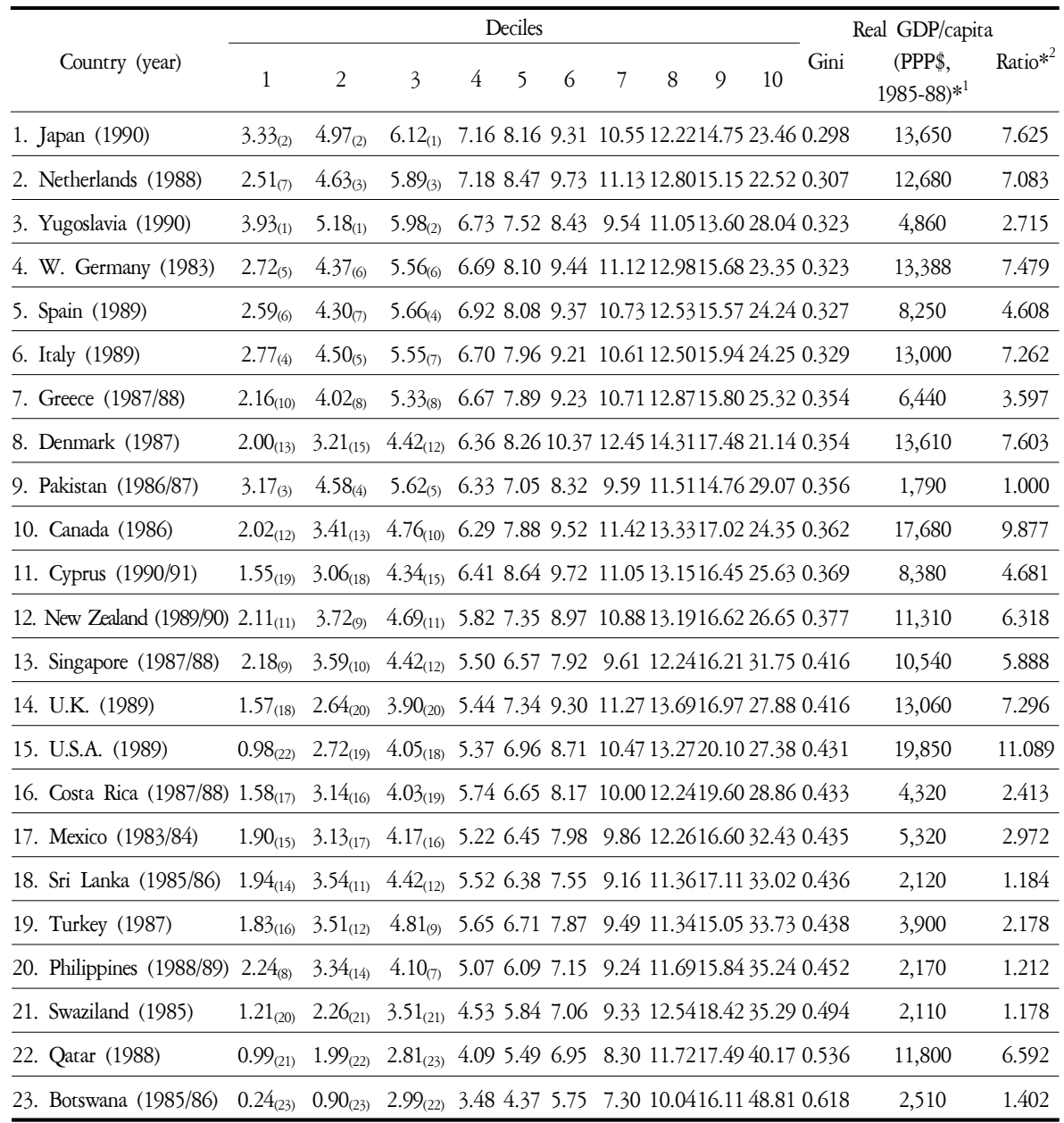

Note: The subscript numbers in parentheses represent the rank of income shares within the same decile.

*1: Source of Real GDP/capita is Human Development Report 1991, the UNDP

*2: Ratio of country A $=$ (Real GDP per capita of country A $) \div$ (Real GDP per capita of Pakistan) Source: Author's estimation.

Figure 1 shows that two Lorenz curves of W. Germany and Pakistan cross. Taking into account that W. Germany's income shares of the bottom $4^{\text {th }}$ and $5^{\text {th }}$ cumulated decile are 19.34 per cent and 27.44 per cent respectively, and those of Pakistan are 19.70 per cent and 26.75 per cent, the point where the Lorenz curves of these two countries cross can be assumed to be between 40 and 50 per cent on the axis of the cumulative proportion of households. 
FIGURE 1: Lorenz curves of W. Germany - Pakistan

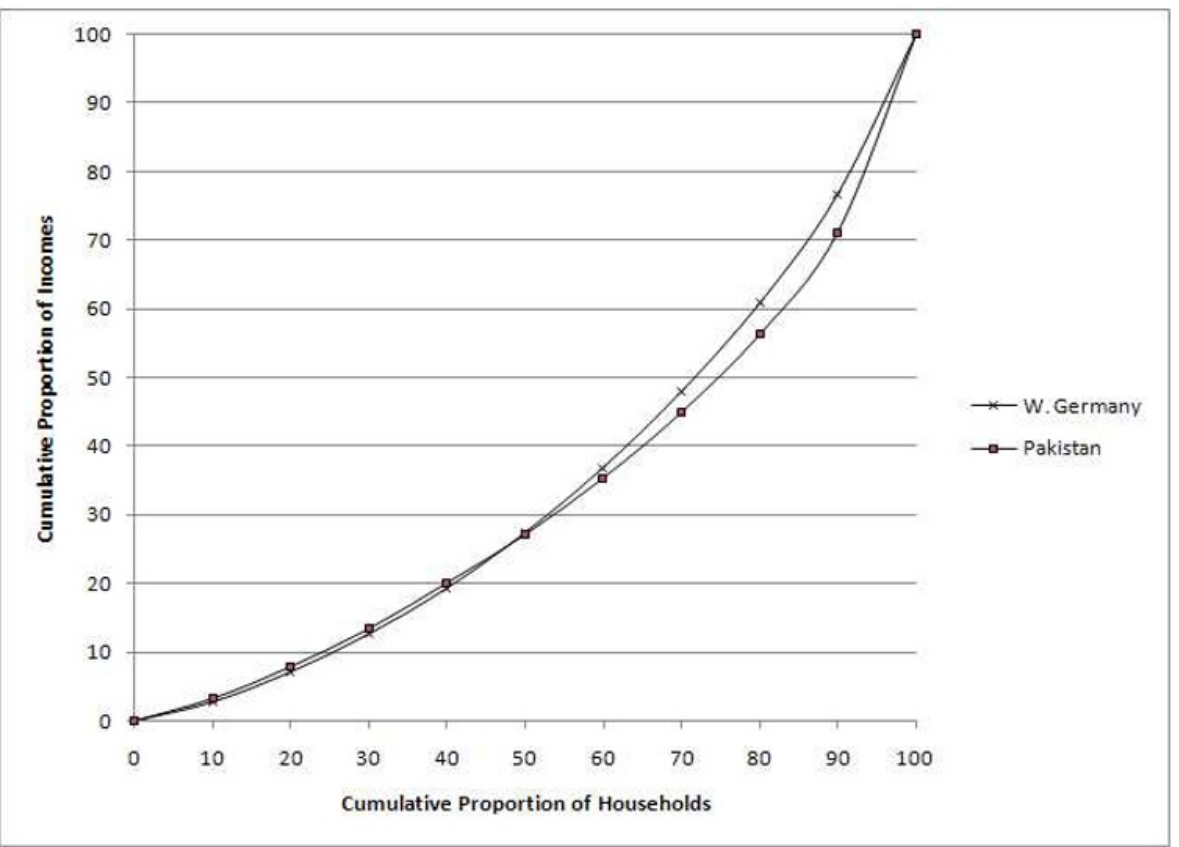

What interpretation can be given to the fact that Lorenz curves cross? Disregarding the question of mean income gap between the two countries, one would say that W. Germany has more inequality at the bottom and less at the top than does Pakistan. Let us now introduce the mean income gap between the two countries which was disregarded in the former case. Taking into account the real GDP per capita (1985-1988) as shown in Table 2, we can estimate that W. Germany has a mean income level more than seven times higher than Pakistan. However, W. Germany is considered as having more inequality at the bottom than Pakistan because of the lower income share received by the bottom deciles. Simple computations reveal that the income share of the bottom $1^{\text {st }}$ decile of W. Germany would be much larger than that of Pakistan. In this circumstance, it is difficult to conceive how W. Germany's household income distribution for classes at the bottom could be regarded as inferior to that of Pakistan. To clear up the ambiguity that frequently arises when comparing distribution, as will be shown in the next section, we need the generalized Lorenz curves which can be drawn from income shares of decile and mean income level. 


\section{EVALUATING WELFARE}

The deciles and Gini coefficients in Table 2 show how the "cake is divided", but they do not reveal the "size of the cake", that is, the mean income level cannot be inferred from the information contained in them. All deciles and Gini coefficients presented in the table are obtained on the assumption that all countries have an identical mean income. However, when we discuss welfare, we are faced with the need for information concerning mean income levels of each country. For this purpose, the real GDP per capita of the countries established by the UNDP has been utilized. For ease of comparing mean income levels of the countries, the ratios of "the real GDP/capita of each country" to "the real GDP/capita of Pakistan" were calculated, then used for combining with the income shares of decile. The reason why the real GDP/capita of Pakistan was considered as a yardstick to estimate the mean income levels of all countries is merely that Pakistan's mean income was the lowest among all of the selected countries. The results of combining the real GDP/capita with the income shares of decile of Table 2 are reported in Table 3. The computed income shares give two kinds of configurations of Lorenz curves in Figure 2. In Table 3, all countries are ranked once again in terms of their mean income levels, and the computed income shares of decile are presented. Let us first look at the case of the UK and Greece, which may give a clear view when their Lorenz and generalized Lorenz curves are compared. Figure 2-(a) shows Lorenz curve of Greece is higher than that of the UK without crossing, in other words, Greece has a more equal income distribution than the UK. Given two income distributions, we simply compute (ratio of mean income) $\mathrm{x}$ (shares of decile) as mentioned above, and plot new curves ( $=$ generalized Lorenz curves) to see whether we have a configuration for which a clear welfare distinction is available. The result is presented in Figure 2-(b). In this figure, as the mean income ratio of the UK is 2.03 times higher than that of Greece, the cumulated income shares of the $10^{\text {th }}$ decile on the axis indicate that the portion of total household incomes in the UK expanded 2.03 times more than that of Greece. Also, its generalized Lorenz curve accumulates computed income shares upwards from decile 0 through 10. The generalized Lorenz curve for the UK (henceforth $G L_{U K}$ ) is now higher than that of Greece, contrary to the case in Figure 2-(a). In carrying out this procedure for all pair-wise comparisons between countries, we can reveal the dominance of welfare levels for every selected country. 
TABLE 3: Computed income shares with mean income ratios

\begin{tabular}{|c|c|c|c|c|c|c|c|c|c|c|}
\hline \multirow{2}{*}{ Country } & \multicolumn{10}{|c|}{ Deciles } \\
\hline & $1 \mathrm{st}$ & $2 \mathrm{nd}$ & $3 \mathrm{rd}$ & $4 \mathrm{th}$ & 5 th & 6th & 7 th & 8 th & 9th & 10th \\
\hline 1. U.S.A. & 10.9 & 30.2 & 44.9 & 59.5 & 77.1 & 96.6 & 116.0 & 147.1 & 222.9 & 303.6 \\
\hline 2. Canada & 20.0 & 33.7 & 47.0 & 62.2 & 77.9 & 94.0 & 113.0 & 131.6 & 168.1 & 240.5 \\
\hline 3. Japan & 25.4 & 37.9 & 46.6 & 54.6 & 62.2 & 71.0 & 80.4 & 93.2 & 112.5 & 178.8 \\
\hline 4. Denmark & 15.2 & 24.4 & 33.6 & 48.3 & 62.8 & 78.9 & 94.6 & 108.8 & 132.9 & 160.7 \\
\hline 5. W. Germany & 20.3 & 32.7 & 41.5 & 50.1 & 60.6 & 70.6 & 83.1 & 97.0 & 117.2 & 174.6 \\
\hline 6. U.K. & 11.4 & 19.3 & 28.5 & 39.7 & 53.6 & 67.8 & 82.2 & 99.9 & 123.8 & 203.4 \\
\hline 7. Italy & 20.1 & 32.7 & 40.3 & 48.6 & 57.8 & 66.9 & 77.1 & 90.8 & 115.8 & 176.1 \\
\hline 8. Netherlands & 17.8 & 32.8 & 41.7 & 50.8 & 60.0 & 68.9 & 78.8 & 90.6 & 107.3 & 159.5 \\
\hline 9. Qatar & 6.55 & 13.1 & 18.5 & 26.9 & 36.2 & 45.8 & 54.7 & 77.2 & 115.3 & 264.8 \\
\hline 10. New Zealand & 13.4 & 23.5 & 29.6 & 36.8 & 46.4 & 56.7 & 68.7 & 83.4 & 105.0 & 168.4 \\
\hline 11. Singapore & 12.8 & 21.1 & 26.1 & 32.4 & 38.7 & 46.6 & 56.6 & 72.1 & 95.5 & 187.0 \\
\hline 12. Cyprus & 7.2 & 14.3 & 20.3 & 30.0 & 40.4 & 45.5 & 51.7 & 61.6 & 77.0 & 120.0 \\
\hline 13. Spain & 11.9 & 19.8 & 26.1 & 31.9 & 37.3 & 43.2 & 49.5 & 57.7 & 71.8 & 111.7 \\
\hline 14. Greece & 7.8 & 14.5 & 19.2 & 24.0 & 28.4 & 33.2 & 38.5 & 46.3 & 56.8 & 91.1 \\
\hline 15. Mexico & 5.6 & 9.3 & 12.4 & 15.5 & 19.2 & 23.7 & 29.3 & 36.4 & 49.4 & 96.4 \\
\hline 16. Yugoslavia & 10.7 & 14.1 & 16.2 & 18.3 & 20.4 & 22.9 & 25.9 & 30.0 & 36.9 & 76.1 \\
\hline 17. Costa Rica & 3.8 & 7.6 & 9.7 & 13.8 & 16.0 & 19.7 & 24.1 & 29.5 & 47.3 & 69.6 \\
\hline 18. Turkey & 4.0 & 7.6 & 10.5 & 12.3 & 14.6 & 17.1 & 20.7 & 24.7 & 32.8 & 73.5 \\
\hline 19. Botswana & 0.3 & 1.3 & 4.2 & 4.9 & 6.1 & 8.1 & 10.2 & 14.1 & 22.6 & 68.4 \\
\hline 20. Philippines & 2.7 & 4.0 & 5.0 & 6.2 & 7.4 & 8.7 & 11.2 & 14.2 & 17.2 & 42.7 \\
\hline 21. Sri Lanka & 2.3 & 4.2 & 5.2 & 6.5 & 7.6 & 8.9 & 10.8 & 13.5 & 20.3 & 39.1 \\
\hline 22. Swaziland & 1.4 & 2.7 & 4.1 & 5.3 & 6.9 & 8.3 & 11.0 & 14.8 & 21.7 & 41.6 \\
\hline 23. Pakistan & 3.2 & 4.6 & 5.6 & 6.3 & 7.1 & 8.3 & 9.6 & 11.5 & 14.8 & 29.1 \\
\hline
\end{tabular}

Source: Author's estimation.

FIGURE 2: Lorenz curves and Generalized Lorenz curves of the UK - Greece

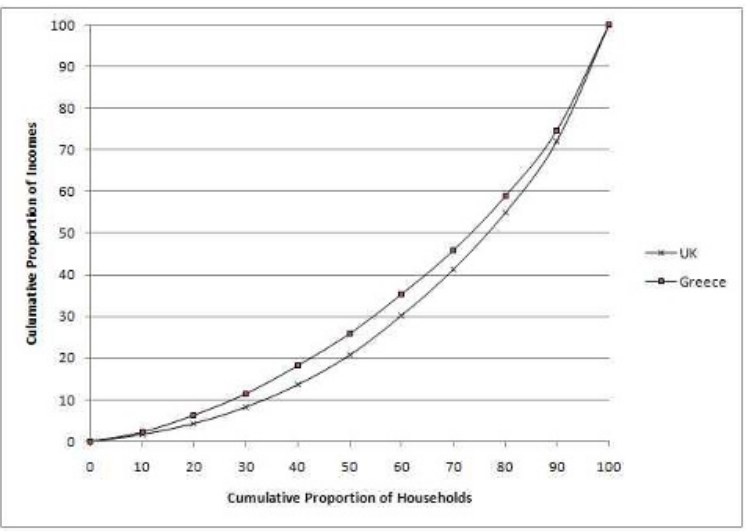

(a) Lorenz curves 


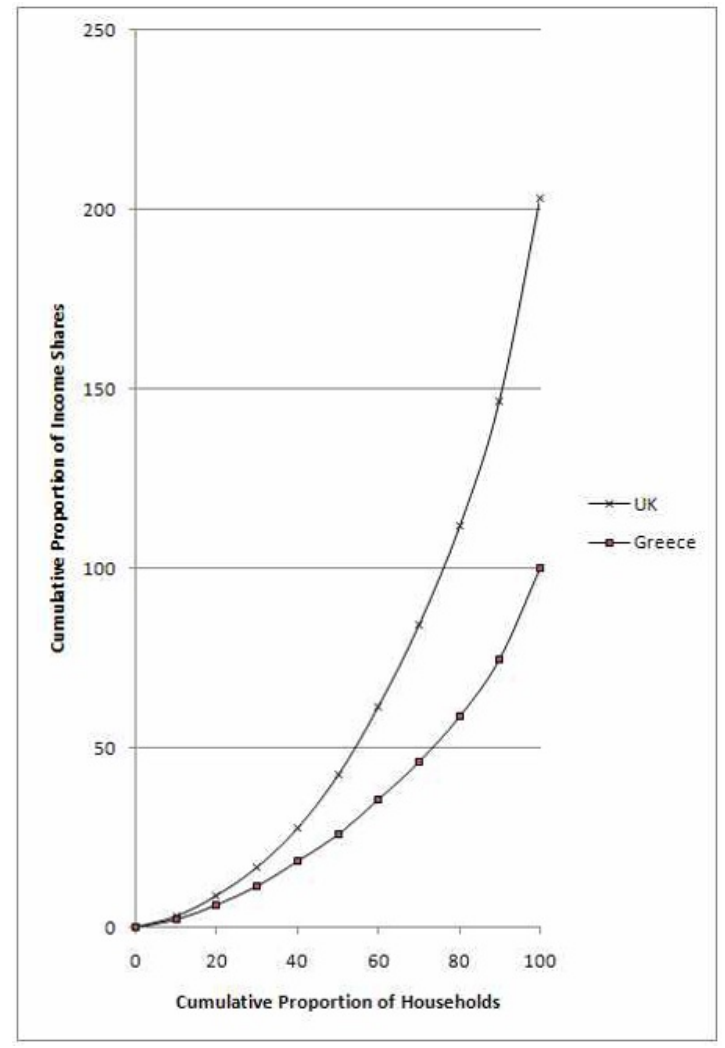

(b) Generalized Lorenz curves

For this purpose, 233 pair-wise comparisons were processed, which are shown in Table 4. During this procedure, it was found that the each pair-wise comparison belonged to one of five different cases. The following is a summary of the five cases which arose from these comparisons.

$1^{\text {st }}$ case: Lorenz curve of country $\mathrm{A}$ (henceforth $L_{A}$ ) is higher than that of country $\mathrm{B}\left(=L_{B}\right)$, mean income level of country A (henceforth $m_{A}$ ) is higher than that of country $\mathrm{B}\left(=m_{B}\right)$.

$2^{\text {nd }}$ case: $L_{A}$ and $L_{B}$ cross, Gini coefficient of country A (henceforth Gini $_{A}$ ) is lower than that of country $\mathrm{B}\left(=G i n i_{B}\right)$, and $m_{A}$ is higher than $m_{B}$, so $G L_{A}$ is higher than $G L_{B}$.

$3^{\text {rd }}$ case: $L_{A}$ and $L_{B}$ cross, Gini ${ }_{A}$ is higher than $G i n i_{B}$, but $m_{A}$ is higher than $m_{B}$, so $G L_{A}$ is higher than $G L_{B}$.

$4^{\text {th }}$ case: $L_{A}$ is lower than $L_{B}$, but $m_{A}$ is higher than $m_{B}$, then $G L_{A}$ is higher than $G L_{B}$.

$5^{\text {th }}$ case: $G L_{A}$ and $G L_{B}$ cross. 
In the $1^{\text {st }}$ case, welfare dominance is obvious and simple to evaluate. As an example, we have Denmark and Mexico. $L_{\text {Denmark }}$ is higher than $L_{\text {Mexico }}$, and $m_{\text {Denmark }}$ is higher than $m_{\text {Mexico }}$, therefore $G L_{\text {Denmark }}$ is higher than $G L_{\text {Mexico }}$ (see Table 2). We find that the welfare of Denmark dominates that of Mexico in every respect, that is, in terms of not only equality level, but also in terms of mean income level. Therefore, we may say that the welfare level of Denmark is superior to that of Mexico. Correspondingly, all comparisons in the $1^{\text {st }}$ case can be judged in this way without any objection. Evidently this is a unanimous case.

In the $2^{\text {nd }}$ case, it is more difficult to evaluate welfare dominance than in the former case. Lorenz curves of countries A and B cross, but Gini $i_{A}$ is lower than $G i n i_{B}$, and $G L_{A}$ is higher than $G L_{B}$ without crossing. If we take into consideration only Gini coefficients and the generalized Lorenz curves, the welfare level of country A will be superior to that of country B. However, the fact that the $L_{A}$ and $L_{B}$ cross hampers our welfare evaluation. Let us look again at the case of W. Germany-Pakistan which belongs to the $2^{\text {nd }}$ case. $L_{W}$.Germany and $L_{\text {Pakistan }}$ cross (see Figure 1). Gini $i_{W . G e r m a n y}$ is lower than Gini $i_{\text {Pakistan }}$ (see Table 2), and $G L_{W . G e r m a n y}$ is higher than $G L_{\text {Pakistan }}$ (see Figure 3). That is, W. Germany generally has more equal income distribution and a higher mean income than Pakistan. Empirically, we might assume that the welfare of W. Germany may dominate that of Pakistan, however, such an evaluation may be a bit hasty. The $3^{\text {rd }}$ case resembles the $2^{\text {nd }}$ one, but the ranking of the two countries, A and B, by Gini coefficients, is reversed. As an example of this case, let us take Canada and Denmark. $L_{\text {Canada }}$ and $L_{\text {Denmark }}$ cross, Gini $i_{\text {Canada }}$ is higher than $G i n i_{\text {Denmark, }}$ but $G L_{\text {Canada }}$ is higher than $G L_{\text {Denmark. According to Table 2, the income }}$ shares of the $1^{\text {st }}, 2^{\text {nd }}$ and $3^{\text {rd }}$ deciles of Canada are bigger than those of Denmark (Canada has more equal income distribution at the lower deciles). In this situation, if we disregard the higher $G L_{\text {Canada, }}$, the Canada-Denmark welfare comparison is more controversial than the former cases.

In the $4^{\text {th }}$ case, the inequality degree of country $A$ is obviously higher than that of country $\mathrm{B}$, but $G L_{A}$ is higher than $G L_{B}$ thanks to its higher mean income level. 
FIGURE 3. Generalized Lorenz curves (W.Germany - Pakistan)

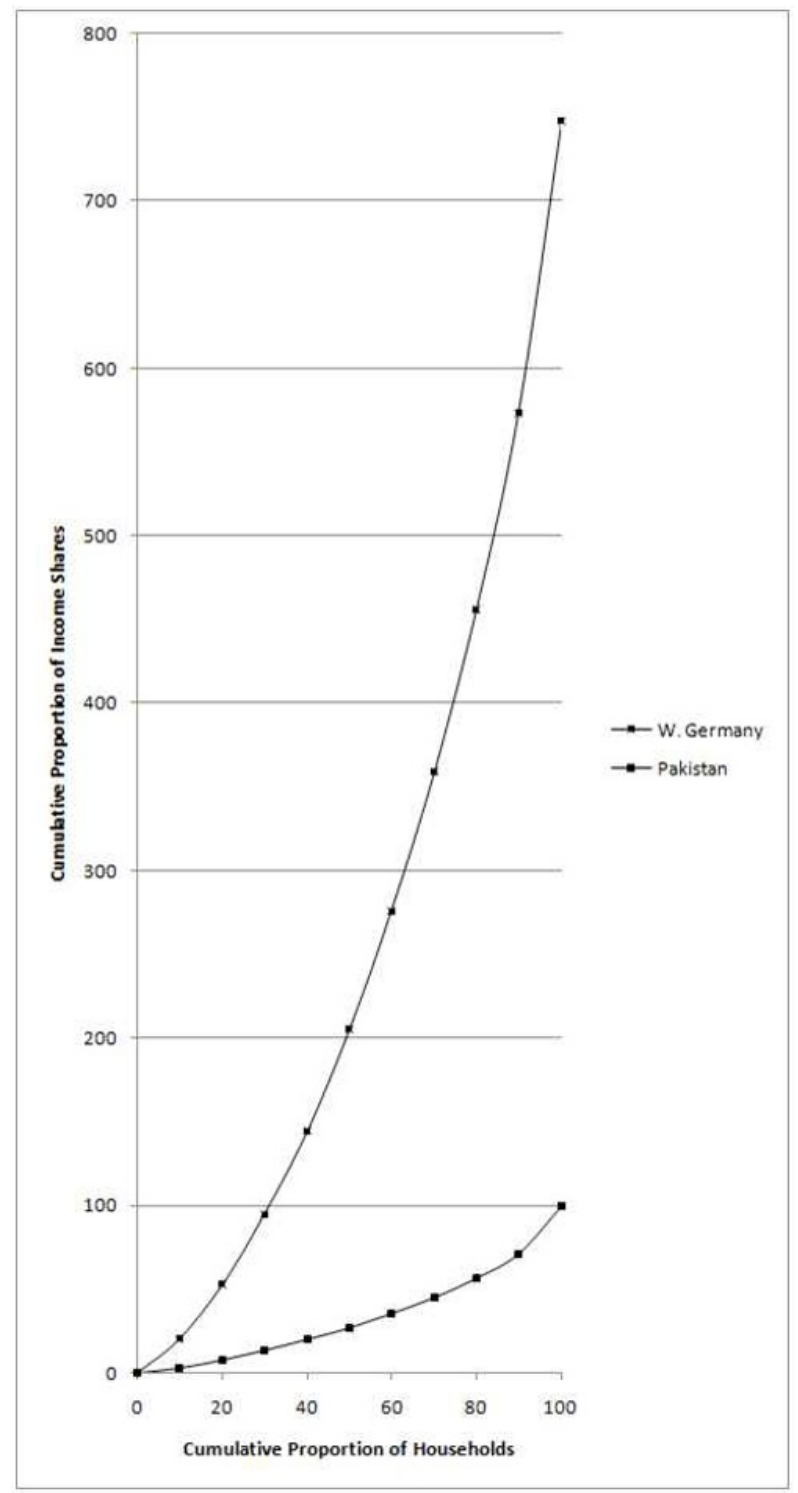

This case, like the $2^{\text {nd }}$ and $3^{\text {rd }}$ cases, shows that the high mean income level compensates for the inequality degree in terms of welfare evaluation. Shorrocks (1983) showed a conclusive result in his theorem about welfare evaluation in all instances involving the $2^{\text {nd }}, 3^{\text {rd }}$ and $4^{\text {th }}$ cases. According to his conclusion, the welfare level of a country whose generalized Lorenz curve is higher than 
the other's would be judged as superior. It suggests that all individuals have a fundamentally identical nature which prefers a bigger share of the cake to smaller cake which is more equally divided.

The welfare comparisons in the $5^{\text {th }}$ case are very complex and make it difficult to evaluate the welfare level. For example, Pakistan has a more equal income distribution than Botswana ( $L_{\text {Pakistan }}$ is higher than $L_{\text {Botswana }}$ and Gini $i_{\text {Pakistan }}$ is lower than Gini $_{\text {Botswana }}$ ), but the mean income of Botswana is over 1.4 times higher than that of Pakistan, thus their generalized Lorenz curves cross: GL Pakistan is lower in the $9^{\text {th }}$ and $10^{\text {th }}$ deciles, but higher in the other deciles, than $G L_{\text {Botsuana }}$. It is difficult to evaluate welfare dominance when generalized Lorenz curves cross (Dardanoni-Lambert, 1988). Furthermore, there may be several cases which generalized Lorenz curves cross not once but several times. According to the Rawlsian maximin criterion (Rawls, 1971), the welfare of a country whose generalized Lorenz curve is higher than other's for poor classes, is higher. However, such an evaluation may not be accepted unanimously. On the other hand, Lambert (1989) proposed a method for comparing welfare levels when generalized Lorenz curves cross, however, his method does not cover overall cases when generalized Lorenz curves cross several times. Anyway, in this study this case remains uninterpreted for those reasons.

Table 4 presents the result of the welfare comparisons conducted with the 23 selected countries. The welfare level of a country was compared with those of the other 22 countries after which results were classified according to the five cases presented above. For example, Table 4 shows that the welfare level of Canada (henceforth $W_{\text {Canada }}$ ) outranks unanimously those of nine countries in the $1^{\text {st }}$ case (UK, Cyprus, Costa Rica, Mexico, Turkey, Philippines, Botswana, Qatar, Swaziland). If we accept Shorrocks' theorem, we can also see that the welfare level of Canada outranks that of the countries in the $2^{\text {nd }}, 3^{\text {rd }}$ and $4^{\text {th }}$ cases. However, the welfare comparisons between Canada and the countries in the $5^{\text {th }}$ case were not counted for the welfare dominance judgement since their generalized Lorenz curves crossed. This is an appropriate moment to observe the changes in the welfare ranking according to each of the five cases, consequently, it is necessary to diversify the criterion of welfare evaluation. The following four hypotheses A, B, C and D are therefore proposed:

Hypothesis $A: W_{A}$ dominates $W_{B}$ only in the 1 st case.

Hypothesis $\mathrm{B}: \mathrm{W}_{\mathrm{A}}$ dominates $\mathrm{W}_{\mathrm{B}}$ only in the 1st and 2nd cases.

Hypothesis $C: W_{A}$ dominates $\mathbb{W}_{B}$ only in the 1st, 2nd and 3rd cases.

Hypothesis D: $\mathbb{W}_{\mathrm{A}}$ dominates $\mathrm{W}_{\mathrm{B}}$ in all of the $1^{\text {st }}, 2^{\text {nd }}, 3^{\text {rd }}$ and $4^{\text {th }}$ cases. 
TABLE 4: Welfare evaluation

\begin{tabular}{llcc}
\hline Country A & \multicolumn{3}{c}{ Country B } \\
\hline & $1^{\text {st }}$ case: Botswana.(1) & $2^{\text {nd }}$ case: Turkey, Philippines, Sri Lanka, Costa Rica, \\
U.S.A. & Mexico, Swaziland, Qatar.(7) & $3^{\text {rd }}$ case: Yugoslavia.(1) & $4^{\text {th }}$ case: Cyprus, Pakistan, \\
& Greece.(3) & $5^{\text {th }}$ case: UK Singapore, Japan, W.Germany, New Zealand, Canada, \\
& Denmark, Italy, Spain, Netherlands.(10) & $A=1, B=8, C=9, D=12$
\end{tabular}

$1^{\text {st }}$ case: UK, Cyprus, Costa Rica, Mexico, Turkey, Philippines, Swaziland, Qatar, Canada Botswana.(9) $2^{\text {nd }}$ case: New Zealand, Singapore, Sri Lanka.(3) $3^{\text {rd }}$ case: Pakistan, Denmark, Greece, Yugoslavia.(4) $4^{\text {th }}$ case: Spain, Netherlands.(2) $5^{\text {th }}$ case: Italy, W.Germany, Japan, USA.(4) $\quad A=9, B=12, C=16, D=18$

$1^{\text {st }}$ case: Spain, Italy, Greece, Pakistan, Cyprus, New Zealand, Singapore, UK, Japan Costa, Rica, Mexico, Sri Lanka, Turkey, Philippines, Swaziland, Qatar, Botswana.(16) $2^{\text {nd }}$ case: Netherlands, Yugoslavia, W.Germany(3) $\quad 3^{\text {rd }}$ case: $(0) \quad 4^{\text {th }}$ case: $(0)$ $5^{\text {th }}$ case: Denmark, USA, Canada.(3) $\quad A=16, B=19, C=19, D=19$ $1^{\text {st }}$ case: Cyprus, UK, Costa Rica, Mexico, Swaziland, Qatar, Botswana.(7) $2^{\text {nd }}$ Denmark case: Pakistan, New Zealand, Singapore, Sri Lanka, Turkey, Philippines.(6) $3^{\text {rd }}$ case: Greece, Spain, Yugoslavia.(3) $4^{\text {th }}$ case: (0) $5^{\text {th }}$ case: Italy, W.Germany, Netherlands, USA, Japan.(5) $\quad A=7, B=13, C=16, D=16$ $1^{\text {st }}$ case: Greece, Cyprus, New Zealand, Singapore, UK, Costa Rica, Mexico, Sri

W.Germany Lanka, Turkey, Philippines, Swaziland, Qatar, Botswana.(13) $2^{\text {nd }}$ case: Italy, Spain, Pakistan.(3) $3^{\text {rd }}$ case: Yugoslavia, Netherlands.(2) $4^{\text {th }}$ case: (0) $5^{\text {th }}$ case: USA, Canada, Denmark.(3) $\quad A=13, B=16, C=18, D=18$ $1^{\text {st }}$ case: Qatar, Botswana, Swaziland.(3) $2^{\text {nd }}$ case: Costa Rica, Mexico, Turkey, UK Philippines, Sri Lanka.(5) $3^{\text {rd }}$ case: Yugoslavia, Pakistan, Cyprus.(3) $4^{\text {th }}$ case: Greece.(1) $5^{\text {th }}$ case: Singapore, New Zealand, Italy, Spain, Netherlands, USA.(6)

$\mathrm{A}=3, \mathrm{~B}=8, \mathrm{C}=11, \mathrm{D}=12$

$1^{\text {st }}$ case: Greece, Cyprus, New Zealand, Singapore, Costa Rica, Mexico, Sri Lanka, Turkey, Philippines, Swaziland, Qatar, Botswana.(12) $2^{\text {nd }}$ case: Pakistan.(1) Italy $\quad 3^{\text {rd }}$ case: Spain, Yugoslavia.(2) $4^{\text {th }}$ case: (0) $5^{\text {th }}$ case: Netherlands, USA, Canada, Denmark, UK.(5) $\mathrm{A}=12, \mathrm{~B}=13, \mathrm{C}=15, \mathrm{D}=15$

$1^{\text {st }}$ case: Greece, Cyprus, New Zealand, Singapore, Costa Rica, Mexico, Turkey, Netherlands Swaziland, Qatar, Botswana, Philippines, Sri Lanka.(12) $2^{\text {nd }}$ case: Spain, Yugoslavia, Pakistan.(3) $3^{\text {rd }}$ case: (0) $4^{\text {th }}$ case: (0) $5^{\text {th }}$ case: USA, Denmark, UK, Italy.(4)

$\mathrm{A}=12, \mathrm{~B}=15, \mathrm{C}=15, \mathrm{D}=15$

$1^{\text {st }}$ case: Botswana. (1) $\quad 2^{\text {nd }}$ case: (0) $3^{\text {rd }}$ case: (0) $4^{\text {th }}$ case: Swaziland, Philippines, Qatar Turkey, Sri Lanka, Mexico, Costa Rica, Pakistan.(7) $5^{\text {th }}$ case: Singapore, New Zealand, Cyprus, Greece, Spain, Yugoslavia.(6) $\quad A=1, B=1, C=1, D=8$

$1^{\text {st }}$ case: Costa Rica, Mexico, Sri Lanka, Turkey, Philippines, Botswana, Swaziland.(7) New Zealand $2^{\text {nd }}$ case: Singapore.(1) $3^{\text {rd }}$ case: Cyprus, Pakistan.(2) $4^{\text {th }}$ case: Greece, Spain, Yugoslavia.(3) $5^{\text {th }}$ case: USA, UK, Qatar.(3) $\quad \mathrm{A}=7, \mathrm{~B}=8, \mathrm{C}=10, \mathrm{D}=13$ $1^{\text {st }}$ case: Mexico, Sri Lanka, Swaziland, Botswana.(4) $2^{\text {nd }}$ case: Costa Rica, Turkey, Singapore $\quad$ Philippines.(3) $3^{\text {rd }}$ case: Cyprus, Greece.(2) $4^{\text {th }}$ case: Pakistan, Spain, Yugoslavia.(3) $5^{\text {th }}$ case: USA, UK, Qatar.(3) $A=4, B=7, C=9, D=12$

Cyprus $\quad 1^{\text {st }}$ case: Swaziland, Botswana.(2) $2^{\text {nd }}$ case: Costa Rica, Mexico, Sri Lanka, Turkey, Philippines.(5) $3^{\text {rd }}$ case: Pakistan.(1) $4^{\text {th }}$ case: (0) $5^{\text {th }}$ case: Yugoslavia, Greece, 
Spain, Qatar.(4)

$\mathrm{A}=2, \mathrm{~B}=7, \mathrm{C}=8, \mathrm{D}=8$

$1^{\text {st }}$ case: Greece, Costa Rica, Mexico, Sri Lanka, Turkey, Philippines, Swaziland, Spain Botswana.(8) $\quad 2^{\text {nd }}$ case: Pakistan.(1) $\quad 3^{\text {rd }}$ case: Yugoslavia.(1) $4^{\text {th }}$ case: (0) $5^{\text {th }}$ case: USA, UK, Qatar, Cyprus.(4) $\quad A=8, B=9, C=10, D=10$

$1^{\text {st }}$ case: Costa Rica, Mexico, Turkey, Botswana, Sri Lanka, Swaziland.(6) $2^{\text {nd }}$

Greece case: Pakistan, Philippines.(2) $\quad 3^{\text {rd }}$ case: (0) $4^{\text {th }}$ case: (0) $5^{\text {th }}$ case: Yugoslavia, Qatar, Cyprus.(3) $\mathrm{A}=6, \mathrm{~B}=8, \mathrm{C}=8, \mathrm{D}=8$

$1^{\text {st }}$ case: Botswana, Swaziland.(2) $2^{\text {nd }}$ case: Sri Lanka, Turkey, Philippines.(3) Mexico $\quad 3^{\text {rd }}$ case: Costa Rica.(1) $\quad 4^{\text {th }}$ case: Pakistan.(1) $\quad 5^{\text {th }}$ case: Yugoslavia.(1)

$A=2, B=5, C=6, D=7$

$1^{\text {st }}$ case: Turkey, Costa Rica, Botswana, Philippines, Sri Lanka, Swaziland, Yugoslavia Pakistan.(7) $2^{\text {nd }}$ case: $(0) \quad 3^{\text {rd }}$ case: $(0) \quad 4^{\text {th }}$ case: $(0) \quad 5^{\text {th }}$ case: Qatar, Cyprus, Greece, Mexico.(4) A=7, B=7, C=7, D=7

\begin{tabular}{|c|c|}
\hline sta $\mathrm{F}$ & $1^{\text {st }}$ case: Botswana, Swaziland.(2) $2^{\text {nd }}$ case: Sri Lanka, Philippines. $(2) 3^{\text {rd }}$ case: \\
\hline \multirow{3}{*}{ urkey } & \\
\hline & , Botswana.(2) $\quad 2^{\text {nd }}$ case: Phil \\
\hline & $4^{\text {th }}$ case: Pakistan.(1) $\quad 5^{\text {th }}$ case: Costa Rica.(1) \\
\hline \multirow{2}{*}{ ana } & $1^{\text {st }}$ case: $(0) \quad 2^{\text {nd }}$ case: $(0) \quad 3^{\text {rd }}$ case: $(0)$ \\
\hline & Sri Lanka, Swaziland, Pakistan.(4) \\
\hline \multirow[b]{2}{*}{ Philippines } & $2^{\text {nd }}$ case: $(0)$ \\
\hline & Sri Lanka, Pakistan, Botswana.(3) \\
\hline \multirow{2}{*}{ ri Lanka } & $1^{\text {st }}$ case: Swaziland.(1) $\quad 2^{\text {nd }}$ case: $(0)$ \\
\hline & Pakistan, Botswana, Philippines.(3) \\
\hline \multirow[b]{2}{*}{ owaziland } & $4^{\text {th }}$ case: $(0) \quad 5^{\text {th }}$ case: Pakistan, \\
\hline & $A=0, B=0, C=0, D=$ \\
\hline \multirow[b]{2}{*}{ dolstall } & $4^{\text {th }}$ case: $(0)$ \\
\hline & Philippines, Sri Lanka, Swaziland.(4) \\
\hline
\end{tabular}

Note: $A=$ number of dominated countries under the hypothesis $A$ $\mathrm{B}=$ number of dominated countries under the hypothesis $\mathrm{B}$ $\mathrm{C}=$ number of dominated countries under the hypothesis $\mathrm{C}$ $\mathrm{D}=$ number of dominated countries under the hypothesis $\mathrm{D}$

Source: Author's estimation on the basis of Table 2 and Table 3.

First of all, in terms of the hypothesis A, the country which dominated the largest number of countries was Japan. The welfare of Japan unanimously dominated those of 16 of the 22 countries. W. Germany follows with 13 countries. Then the Netherlands and Italy outranked 12 countries. On the other hand, Pakistan, Swaziland, Botswana failed to outrank any country. Under hypothesis B, Japan outranked also the largest number of countries with 19 countries followed by W. Germany, the Netherlands, Denmark and Italy. Once again, Pakistan, Swaziland and Botswana did not succeed in dominating any country. Under hypothesis $\mathrm{C}$, the situation is similar to that of hypotheses $\mathrm{A}$ and $\mathrm{B}$. However, it can be seen that Canada, Denmark, the USA, and the UK improved their 
ranking. Hypothesis D corresponds to the Shorrocks' theorem. Under this hypothesis, the welfare level of the countries can be ranked and their rankings compared as follows.

TABLE 5: Welfare ranking under hypothesis D

\begin{tabular}{clrl}
\hline Ranking & \multicolumn{1}{c}{ Country } & Ranking & \multicolumn{1}{c}{ Country } \\
\hline 1 & Japan(A:1/B:1/C:1/D:1) & 12 & Qatar(A:17/B:18/C:18/D:12) \\
\hline 2 & Canada(A:5/B:6/C:3/D:2) & 12 & Cyprus(A:13/B:12/C:12/D:12) \\
\hline 2 & W. Germany(A:2/B:2/C:2/D:2) & 15 & Yugoslavia(A:7/B:12/C:14/D:15) \\
\hline 4 & Denmark(A:7/B:4/C:3/D:4) & 15 & Mexico(A:13/B:15/C:15/D:15) \\
\hline 5 & Netherlands(A:3/B:3/C:5//D:5) & 17 & Costa Rica(A:13/B:16/C:16/D:17) \\
\hline 5 & Italy(A:3/B:4/C:5/D:5) & 17 & Turkey(A:13/B:17/C:17/D:17) \\
\hline 7 & New Zealand(A:7/B:8/C:8/D:7) & 19 & Philippines(A:17/B:18/C:18/D:19) \\
\hline 8 & USA(A:17/B:8/C:10/D:8) & 19 & Sri Lanka (A:17/B:18/C:18/D:19) \\
\hline 8 & UK(A:12/B:8/C:7/D:8) & 21 & Botswana(A:21/B:21/C:21/D:21) \\
\hline 8 & Singapore(A:11/B:12/C:10/D:8) & 21 & Swaziland(A:21/B:21/C:21/D:21) \\
\hline 11 & Spain(A:6/B:7/C:8/D:11) & 21 & Pakistan(A:21/B:21/C:21/D:21) \\
\hline 12 & Greece(A:10/B:8/C:12/D:12) & & \\
\hline
\end{tabular}

Source: Author's estimation

Rankings in Table 5 are on the basis of results obtained under hypothesis D. The welfare levels of the countries are ranked, in parentheses, according to 4 different hypotheses. This table provides a rapid overview of the pattern of welfare dominance of the countries. As a result, the welfare level of Japan dominated the largest number of those of the countries under every hypothesis. Also, W. Germany has kept the same ranking under every hypothesis. By the way, there are several countries whose ranking changed remarkably according to alternative hypotheses. Canada, Denmark, the USA and the UK improved their ranking as the hypotheses changed from A to D. Quite to the contrary, the ranking of Yugoslavia dropped considerably. This is because, as mentioned above, there is a tendency to be more weighted to the mean income level when proceeding from hypothesis A to D. That is, Canada, Denmark, the USA and the UK have a relatively high inequality degree in comparison with their mean income levels, while the contrary holds true for the socialist countries. However, more than half of the countries do not show a conspicuous shift in their ranking according to the alternative hypotheses.

We have compared so far the inequality levels of household income and welfare between countries selected on a worldwide basis to an earlier period of the end of the Cold War. In this step, it would be meaningful to compare the welfare ranking in the 1980s with that in the 2000s. However, due to lack of welfare ranking in the 2000s, Gini coefficients in the 2000s and income 
ratios in 2009 were compared with those in the 1980s. In Table 6, Gini and the Ratio (1985-88) are the same as those in Table 2 and Gini-ILO is from the LABORSTAT internet established by the ILO. The Ratio (2009) was calculated in the same way as the Ratio in Table 2 on the basis of GDP per capita (PPP) in the 2011 Human Development Report (UNDP). As can be seen from Gini and Gini-ILO in Table 6, the six countries' Gini coefficients varied over time but significant trends were not found. However, there were considerable changes between the Ratios of 1985-88 and 2009, such as changes in the ranking of countries and the enlarged income gap between high income countries and low income countries. The changes allow us to forecast that income inequality and welfare ranking in the 1980s certainly must have been changed in the 2000s. For this comparison, income inequality and welfare ranking in the 2000s should be estimated by using the data from the 2000s. However, the estimation is too large to conduct in this study, and thus, it will have to leave to be done in subsequent research.

TABLE 6: Welfare ranking under hypothesis D

\begin{tabular}{|c|c|c|c|c|c|}
\hline Country & & $\begin{array}{c}\text { Gini*1 } \\
\text { (year) }\end{array}$ & $\begin{array}{c}\begin{array}{c}\text { Gini-ILO*2 } \\
\text { (year) }\end{array} \\
\end{array}$ & $\begin{array}{c}\text { Ratio* }^{3} \\
(1985-88)\end{array}$ & $\begin{array}{l}\text { Ratio**4 } \\
(2009)\end{array}$ \\
\hline 1. Japan & 0.298 & $(1990)$ & n.a. & 7.625 & 12.425 \\
\hline 2. Netherlands & 0.307 & $(1988)$ & n.a. & 7.083 & 15.591 \\
\hline 3. Yugoslavia & 0.323 & $(1990)$ & n.a. & 2.715 & n.a. \\
\hline 4. W. Germany & 0.323 & (1983) & n.a. & 7.479 & $13.928 * 5$ \\
\hline 5. Spain & 0.327 & (1989) & $0.316(2002)$ & 4.608 & 12.323 \\
\hline 6. Italy & 0.329 & $(1989)$ & n.a. & 7.262 & 12.430 \\
\hline 7. Greece & 0.354 & $(1987 / 88)$ & n.a. & 3.597 & 11.352 \\
\hline 8. Denmark & 0.354 & $(1987)$ & $0.39(2003)$ & 7.603 & 14.458 \\
\hline 9. Pakistan & 0.356 & $(1986 / 87)$ & n.a. & 1.000 & 1.000 \\
\hline 10. Canada & 0.362 & (1986) & n.a. & 9.877 & 14.491 \\
\hline 11. Cyprus & 0.369 & $(1990 / 91)$ & $0.264(2003)$ & 4.681 & 11.824 \\
\hline 12. New Zealand & 0.377 & $(1989 / 90)$ & n.a. & 6.318 & 11.113 \\
\hline 13. Singapore & 0.416 & $(1987 / 88)$ & $0.481(2000)$ & 5.888 & 19.407 \\
\hline 14. U.K. & 0.416 & (1989) & $0.339(2003 / 04)$ & 7.296 & 13.475 \\
\hline 15. U.S.A. & 0.431 & (1989) & n.a. & 11.089 & 17.627 \\
\hline 16. Costa Rica & 0.433 & $(1987 / 88)$ & n.a. & 2.413 & 4.257 \\
\hline 17. Mexico & 0.435 & $(1983 / 84)$ & n.a. & 2.972 & 5.465 \\
\hline 18. Sri Lanka & 0.436 & $(1985 / 86)$ & n.a. & 1.184 & 1.829 \\
\hline 19. Turkey & 0.438 & $(1987)$ & n.a. & 2.178 & 5.239 \\
\hline 20. Philippines & 0.452 & $(1988 / 89)$ & $0.482(2000)$ & 1.212 & 1.358 \\
\hline 21. Swaziland & 0.494 & (1985) & n.a. & 1.178 & 1.916 \\
\hline 22. Qatar & 0.536 & (1988) & n.a. & 6.592 & 35.025 \\
\hline 23. Botswana & 0.618 & $(1985 / 86)$ & n.a. & 1.402 & 5.130 \\
\hline
\end{tabular}


Note: $* 1$ and $* 3$ are from Table 2

*2 is from the Laborsta internet ILO

*4 is estimated on the basis of GDP per capita (PPP)

*5 is GDP per capita in Germany

n.a.: non available

Source: Author's estimation, http://laborsta.ilo.org/default.html Laborsta internet ILO, UNDP(2011)

\section{SOME CONCLUDING REMARKS}

This study explores how the levels of welfare and household income inequality are ranked among the countries selected on a worldwide basis in the 1980s. The data of the HIES we used are those concerning household income before deduction of income or other direct taxes and social security contributions. Taking into account that income or direct taxes are major means of correcting the inequality gap, and that use of household income per household data may overestimate income level of large households and, correspondingly, underestimate that of small households, the results we obtained may be different from those based on data concerning household income per household after tax or household income per equivalent unit or per head.

In concluding this study, it seems appropriate to comment on what this study has shown about comparative household income distribution and welfare. The income distribution results present the ranking of the countries by the Gini coefficients and Lorenz curves. However, drawbacks of the Gini coefficients and Lorenz curves may be found when Lorenz curves cross. Introducing mean income level into the income distribution results could avoid the problems and generate a new ranking for social welfare. Four different hypotheses were set up to evaluate social welfare levels of the countries; the $1^{\text {st }}$ hypothesis was a unanimous case and the $4^{\text {th }}$ one came from the Shorrocks theorem. The Shorrocks theorem was based on the assumption that people prefer a higher income level, but at the same time have a disutility due to inequality aversion or risk aversion in their nature. Looking at the welfare ranking changes according to the four hypotheses, it can be said that the social welfare rankings of Canada, Denmark, the USA, and the UK could be kept high by rather their relatively high mean income. Yugoslavia failed to keep a high ranking because of their relatively low mean income. In fact, the welfare ranking is estimated by indirect comparisons on the basis of the number of dominated countries. The indirect comparisons are used as a second best method to allow the comparison of welfare levels between countries when their generalized Lorenz curves cross. The results of social welfare ranking therefore are not absolutely unanimous. Also, we found that the income ratios changed a lot over time, and accordingly, it is necessary to update the 
welfare ranking of the countries by using data from the 2000s for an accurate comparison with that just before the end of the Cold War in subsequent research. 


\section{APPENDIX: Statistical Methods ${ }^{1}$}

\section{1) General interpolation method}

Suppose a distribution with $N$ income units which are grouped into income classes; $\left(\mathrm{x}_{0}\right.$ to $\left.\mathrm{x}_{1}\right),\left(\mathrm{x}_{1}\right.$ to $\left.\mathrm{x}_{2}\right),\left(\mathrm{x}_{2}\right.$ to $\left.\mathrm{x}_{3}\right), \ldots,\left(\mathrm{x}_{\mathrm{T}}\right.$ to $\left.\mathrm{x}_{\mathrm{T}+1}\right)$, the Gini coefficient in terms of the linear interpolation method (henceforth GCL) can be estimated: $G C L=1-\sum_{t=1}^{T+1} f_{t}\left(q_{t}+q_{t-1}\right)$-------(1). $f_{t}$ is the relative frequency of the $t^{\text {th }}$ income class $\left(=n_{t} / N\right.$ where $n_{t}$ is the number of income units within $t^{\text {th }}$ income class), and $q_{t}=(1 / \mu) \Sigma \mu_{\mathrm{t}} f_{t}$ where $\mu_{\mathrm{t}}$ is the mean income in the $\mathrm{t}^{\mathrm{th}}$ income class and $\mu$ is the overall mean income. The general interpolation device makes it possible to derive the equation of the Lorenz curve within each income class by using a specified (continuous differentiable) function. The Gini coefficient in terms of the general interpolation method (henceforth "GCI") is obtained from $G C I=G C L+\left[\left(\frac{1}{\mu}\right) \sum_{t=1}^{T+1} f_{t}^{2} \mu_{t} G_{t}\right]$------(2). In eq. (2), $G_{t}$ is the Gini coefficient for the $t^{\text {th }}$ income class and it can be measured by means of various (continuous differential) functions: third - degree polynomial function, four - degree polynomial function, linear density function and quadratic density function. According to results of our empirical estimation, the inequality measures estimated by all four methods were very close to each other, and the subtle difference could almost be ignored. Therefore the Lorenz curve within each income class is statistically inferred by means of the third-degree polynomial function, except the first and the last open-ended classes. $G_{t}$ on the basis of the third -degree polynomial

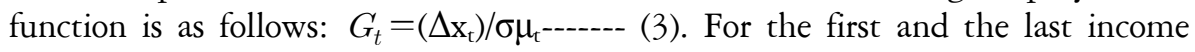
classes which are generally open -ended, the Pareto curves can be fitted to the two income classes. $G_{t}$ is given by: $G_{1}=\left(x_{1}-\mu_{1}\right) /\left(x_{1}+\mu_{1}\right)$------- (4), $G_{T+1}=\left(\mu_{T+1}-x_{T}\right) /\left(\mu_{T+1}+x_{T}\right)$--------- (5). Thus GCI in eq. (2) can be obtained from using (3), (4) and (5).

\section{2) Kakwani-Podder method.}

When the original sources of certain countries do not report income classes but instead report deciles or quintile, the above-described method cannot estimate the Gini coefficients. Furthermore, it does not provide any information on the skewness of the Lorenz curve, that is, the Lorenz curve may be symmetric or skewed toward lower end $(0,0)$ or upper end $(1,1)$ of coordinates despite the same inequality value. Kakwani-Podder introduced a coordinate system for the Lorenz curve, which would be able to avoid the two difficulties of the linear 
interpolation method. Suppose a point " $P$ " on the Lorenz curve with coordinates $\left(F, F_{1}\right)$ and another point " $Q$ " on the egalitarian line, and that $P Q$ is the perpendicular drawn on the egalitarian line in Figure 4. $O M=O L+L M$, $Q L=Q N+N L, O L=L Q=\pi / \sqrt{2}, N Q=N P=\eta / \sqrt{2}$ where $\eta$ is the length $P Q$, and $\pi$ is the distance $O Q$. Thus, $\pi=(F+F 1) / \sqrt{2}$------ $(6)$ and $\eta=(F-F 1) / \sqrt{2}$

FIGURE 4. Lorenz Curve

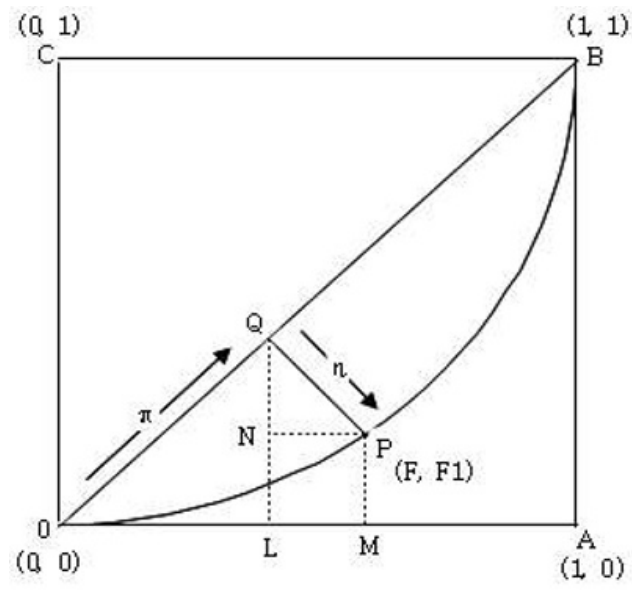

Kakwani and Podder show the equation of the Lorenz curve as follows: $\eta=a \pi^{\alpha}(\sqrt{2}-\pi)^{\beta}$ (8) $a>0, \alpha>0$ and $\beta>0$. The restriction $a>0$ implies that the Lorenz curve lies below the egalitarian line and $\alpha>0$ and $\beta>0$ ensures that $\eta=0$ when $\pi=0$ and also when $\pi=\sqrt{2}$. The Lorenz curve is symmetric if $\alpha=\beta$, skewed toward the upper end $(1,1)$ if $\beta>\alpha$, and skewed toward the lower end $(0,0))$ otherwise. To obtain the parameters $a, \alpha$ and $\beta$, first, eq. (8) is transformed into $\log$ form, then the least squares estimate is used. $\log \eta=\log a+\alpha \log \pi+\beta \log (\sqrt{2}-\pi)$------- (9) Here, as the coordinates $\left(F, F_{1}\right)$ of the point $P$ on the Lorenz curve can be expressed by $\left(p_{t}, q_{t}\right)$ where $p_{t}$ is the cumulative relative frequency of households receiving income equal to or less than $t^{t h}$ mean income and $\mathrm{q}_{\mathrm{t}}$ is the cumulative proportion of income received by those households, (6) and (7) are replaced by the consistent estimators $z_{t}$ and $y_{t}: z_{t}=\left(p_{t}+q_{t}\right) / \sqrt{2}$--------- (6)' and $y_{t}=\left(p_{t}-q_{t}\right) / \sqrt{2}$--------- (7)' Then, in terms of (6)' and (7)', eq. (9) can be written as $\log y_{t}=a^{\prime}+\alpha \log z_{t}+\beta \log \left(\sqrt{2}-z_{t}\right)+w_{1 t}-----$ (10) where $a^{\prime}=\log a$ and $w_{1 t}$ is a random disturbance. Once the parameters $a, \alpha$ and $\beta$ are estimated, the Gini coefficients can be calculated by using the following formula presented 
by Kakwani -Podder (henceforth $G_{K-P}$ ): $G_{K-P}=2 a(\sqrt{2})^{1+\alpha+\beta} B(1+\alpha, 1+\beta)$ (11) where $B(1+\alpha, 1+\beta)$ is the Beta function.

\section{3) Pareto method}

When data provide income classes, mean income and household share, deciles can be computed by using Pareto method which has been widely used. The Pareto distribution with parameters $\mathrm{A}$ and $\lambda$ is defined as follows: $F(x)=(x / A)^{\lambda}$, if $\lambda \geq 0$----- (12), $F(x)=1-(x / A)^{\lambda}$, if $\lambda \leq 0$----- (13) where $F(x)$ is a distribution function, and $A$ and $\lambda$ are unspecified parameters. Based on the Pareto assumption, deciles can be obtained from $q_{(p)}=q_{t}+\beta_{t}\left(p^{(1+\lambda) / \lambda}-p_{t}^{(1+\lambda)}\right)$------ (14) where $q_{(p)}$ is the cumulative income share of each decile: $p=\{0.1,0.2,0.3, \ldots . ., 1\}, p_{t}$ $\leq p \leq p_{t+1}$. It should be noted that $\mathrm{q}_{(\mathrm{p})}$ is greater than or equal $q_{t}$ : if $q_{(p)}>q_{t}$, $p^{(1+\lambda) / \lambda}-p_{t}^{(1+\lambda)}>0$, and if $q_{(p)}=q_{t}, p^{(1+\lambda) / \lambda}-p_{t}^{(1+\lambda)}=0$ Here, $\beta_{t}$ and $\lambda$ are derived by $\beta_{\mathrm{t}}=\left(\mathrm{q}_{\mathrm{t}+1}-\mathrm{q}_{\mathrm{t}}\right) /\left(\mathrm{p}_{\mathrm{t}+1}^{(1+\lambda) / \lambda}-\mathrm{p}_{\mathrm{t}}^{(1+\lambda)}\right)_{------}(15)$ and $\lambda=\log \left(p_{t+1}-q_{\mathrm{t})} / \log \left(x_{t+1} / x_{t}\right)\right.$ (16)

\section{4) Beta Lorenz curve method}

In order to apply the Pareto method, it is necessary to obtain income classes, mean income of each income class and household share. When, however, data do not provide income class, deciles can be computed by estimating the Beta Lorenz curve (Kakwani 1981). The Beta Lorenz curve method provides a convenient estimation of data in the study of income distributions. Kakwani shows the equation of the Beta Lorenz curve as follows: $L(p)=p-a p^{\alpha}(1-p)^{\beta}$----- (17) where $\mathrm{p}$ is the cumulative relative frequency of individuals (households) earning income less than or equal to a certain amount of income $\mathrm{x}, \mathrm{a}, \alpha$ and $\beta$ are the parameters, and are assumed to be $0<\alpha \leq 1$ and $0<\beta \leq 1$. It is noted that $L(p)=0$ for both $p=0$ and $p=1$. To compute the parameters $a$, $\alpha$ and $\beta$, first, eq. (17) is transformed into $\log$ form, then the least squares estimate is used: $\log (p-L(p))=a^{\prime}+\alpha \log p+\beta \log (1-p)+w$, where $a^{\prime}=$ $\log a$ and $w$ is random distrubance. 


\section{REFERENCES}

Atkinson, A. B. 2007. More on the Measurement of Inequality. Journal of Economic Inequality 6: 277-283.

Atkinson, A. B. and Micklewright, J. 1992. Economic transformation in Eastern Europe and the distribution of income. Cambridge: Cambridge University Press.

Chiu, H. W. 2007. Intersecting Lorenz Curves, the Degree of Downside Inequality Aversion, and Tax Reforms. Social Choice and Welfare 28: 375-399.

Cowell, F. A. and Flachaire, E. 2007. Income Distribution and Inequality Measurement: The Problem of Extreme Value. Journal of Econometrics 105: 1044-1072.

Cowell, F. A. and Victoria-Feser, M.-P. 2002. Welfare Rankings in the Presence of Contaminated Data. Econometrica 70: 122-133.

Danziger, S. and Taussig M. K. 1979. The income unit and the anatomy of income distribution. Review of Income and Wealth 25(4): 365-375.

Dardanoni, V. and Lambert, P. J. 1988. Welfare rankings of income distributions: a role for variance and some insights for tax reform. Social Choice and Welfare 5(1): 1-17.

Dutta, B. and Esteban, J. 1992. Social welfare and equality. Social Choice and Welfare 9: 267-276.

Foster, J. E. and Shorrocks A. F. 1988. Poverty orderings and welfare dominance. Social Choice and Welfare 5: 179-198.

ILO. 1988. Current International Recommendations on Labour Statistics. Geneva: International Labour Office.

ILO. 1994. Sources and Methods: Labour Statistics, volume 6 Household income and expenditure survey. $1^{\text {st }}$ Ed. Geneva: International Labour Office.

ILO. 1995. Household Income-Expenditure Statistics. $4^{\text {th }}$ Ed. Geneva: International Labour Office.

Jain, S. 1975. Size distribution of income: A compilation of data. The World Bank: Washington D.C.

Kakwani, N. C. 1973. On the estimation of Lorenz curves from grouped observations. International Economics Review 14(2): 278-292.

Kakwani, N. C. 1976. On the estimation of income inequality measures from grouped observations. Review of Economic Studies 43: 483-492.

Kakwani, N.C. 1980. Income inequality and poverty: Methods of estimation and policy applications. The World Bank Research Publication: Oxford University Press.

Kakwani, N. C. 1981. Welfare measures: An international comparison. Journal of Development Economics 8: 21-45.

Kakwani, N. C. 1984. Welfare ranking of income distributions. Advances in Econometrics 3: 191-213. 
Kakwani, N. C. and Podder, N. 1976. Efficient estimation of the Lorenz curve and associated inequality measures from grouped observations. Econometrica 44: $137-148$.

Lambert, Peter J. 1989. The distribution and redistribution of income: A mathematical analysis. Cambridge: Basil Blackwell.

Mehran, F. 1975. Dealing with grouped income distribution data. World Employment Programme Research: Income distribution and Employment Programme, Working Paper, WEP 2-23/ WP 20, ILO, Geneva.

Milanovic, B. 1992. Income distribution in late socialism: Poland, Hungary, Czechoslovakia, Yugoslavia and Bulgaria compared. The World Bank Research Paper series, Paper No. 1, March. Washington D.C.

Nozick, R. 1974. Anarchy, State, and Utopia. New York: Basic Books.

Rawls, John. (1971). A Theory of Justice. Cambridge, Harvard University.

Shorrocks, A. F. 1983. Ranking income distributions. Economica 50: 1-17.

UNDP. 1991. Human development Report. New York: Oxford University Press.

UNDP. 2011. Human development Report. New York: Oxford University Press.

http://laborsta.ilo.org/default.html Laborsta Internet ILO 